\title{
厳密な線形化によるリニア誘導モータの非線形制御*
}

川田 昌克** 井上 和夫***

\section{Nonlinear Control of Linear Induction Motors Using Exact \\ Linearization*}

Masakatsu KAWATA** and Kazuo InOuE***

\section{1.はじめに}

近年, 堅牢性に優れた誘導モー夕（IM）が ACサーボ モータとして使用されつつある. 本稿で対象とするリニ ア誘導モー夕 (LIM) は回転機であるIM の固定子 (1 次 側), 可動子 (2 次側) おょよびギャップを直線上に引き伸 ばすことにより，電気エネルギーを直接直線的な機械エ ネルギーに変換する推力発生装置である1). IM と違い, LIM の諸定数の值は相によって異なるため,このことを 無視した制御則を用いると, 2 次磁束や推力に脈動を生 じてしまう.そこで, 本稿では, 筆者らがこれまでに提 案してきた IM の非線形制御法3)を LIM の場合に拡張 し, 2 次磁束や推力の脈動を生じない制御を実現する.

\section{LIM の数学モデル}

Fig. 1 に示す片側式 LIM の定数はその構造上, $a, b$, $c$ 相の各相によって異なる。この相非対称性を考慮する と, 参考文献 2)に示されているように, 固定子に固定さ れた $d-q$ 座標系におけるLIM の数学モデルは, 非線形 項 $\omega_{2 e} \psi_{2 d}, \omega_{2 e} \psi_{2 q}, F_{e}$ を含んだ次式のようになる.

$$
\begin{aligned}
& p \psi_{2 d}=-a_{r_{11} d} \psi_{2 d}-\omega_{2 e} \psi_{2 q}+a_{r_{12} d} i_{1 d} \\
& p \psi_{2 q}=-a_{r_{11} q} \psi_{2 q}+\omega_{2 e} \psi_{2 d}+a_{r_{12} q} i_{1 q}
\end{aligned}
$$

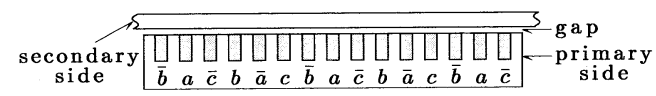

Fig. 1 Linear induction motor

* 原稿受付 1998 年 3 月 11 日

** 舞鶴工業高等専門学校 電子制御工学科 Department of Control Engineering, Maizuru National College of Technology; 234 Aza-Shiroya, Maizuru city, Kyoto 625-8511, JAPAN

*** 立命館大学 理工学部 Faculty of Science and Engineering, Ritsumeikan University; 1-1-1 Noji-Higashi, Kusatsu city, Shiga 525-8577, JAPAN

Key Words: linear induction motor, exact linearization, noninteracting control.

$$
\begin{aligned}
& p i_{1 d}=a_{r_{21} d} \psi_{2 d}+a_{i_{21} d} \omega_{2 e} \psi_{2 q} \\
& -a_{r_{22} d} i_{1 d}+b_{r_{2} d} v_{1 d} \\
& p i_{1 q}=a_{r_{21} q} \psi_{2 q}-a_{i_{21} q} \omega_{2 e} \psi_{2 d} \\
& -a_{r_{22} q} i_{1 q}+b_{r_{2} q} v_{1 q} \\
& p V_{2 m}=\frac{F_{e}-F_{L}}{W} \\
& F_{e}=\lambda_{q} \psi_{2 d} i_{1 q}-\lambda_{d} \psi_{2 q} i_{1 d}+\delta \psi_{2 d} \psi_{2 q} \\
& \bar{a}_{r_{11}}=\frac{a_{r_{11} d}+a_{r_{11} q}}{2}, \widetilde{a}_{r_{11}}=\frac{a_{r_{11} d}-a_{r_{11} q}}{2}
\end{aligned}
$$

を満足するパラメータテ, 〜で置き換えると, 〜および $\delta$ を零とした $(1) \sim(5)$ 式は, 諸定数の相非対称性を考慮し ていない非線形モデルとなり, IM と同様の形式となる.

\section{LIM の非線形制御}

\section{1 非線形補償の導出}

以下では記述の簡単化のため, 中間変数 


$$
\left\{\begin{array}{l}
\bar{\xi}_{1}=\psi_{2 d}^{2}+\psi_{2 q}^{2} \\
\bar{\xi}_{2}=\psi_{2 d} i_{1 d}+\psi_{2 q} i_{1 q} \\
\bar{\xi}_{3}=\psi_{2 d} i_{1 q}-\psi_{2 q} i_{1 d} \\
\bar{\xi}_{4}=i_{1 d}^{2}+i_{1 q}^{2}
\end{array},\left\{\begin{array}{l}
\widetilde{\xi}_{1}=\psi_{2 d}^{2}-\psi_{2 q}^{2} \\
\widetilde{\xi}_{2}=\psi_{2 d} i_{1 d}-\psi_{2 q} i_{1 q} \\
\widetilde{\xi}_{3}=\psi_{2 d} i_{1 q}+\psi_{2 q} i_{1 d} \\
\widetilde{\xi}_{4}=i_{1 d}^{2}-i_{1 q}^{2}
\end{array}\right.\right.
$$

を用いて議論する.まず, $\left|\boldsymbol{\psi}_{2}\right|, V_{2 m}$ をそれらの目標值に 追従させることが制御目的であることを考慮し，出力を

$$
y_{1}=z_{11}=\bar{\xi}_{1}\left(=\left|\boldsymbol{\psi}_{2}\right|^{2}\right), y_{2}=z_{21}=V_{2 m}
$$

と定義すると, 簡単な計算から $\left|\psi_{2}\right| \neq 0$ であるような領 域 $U$ で $y_{1}, y_{2}$ の相対次数が共に 2 となることがわか る.また, $y_{1}=z_{11}$ の時間微分は $z_{11}$ と

$$
z_{12}=\bar{\xi}_{2}-\frac{\widetilde{a}_{r_{11}} \widetilde{\xi}_{1}-\widetilde{a}_{r_{12}} \widetilde{\xi}_{2}}{\bar{a}_{r_{12}}}
$$

の線形結合, $y_{2}=z_{21}$ の時間微分は推力 $F_{e}$ に相当する

$$
z_{22}=\bar{\xi}_{3}-\frac{\widetilde{\lambda} \tilde{\xi}_{3}-\delta \psi_{2 d} \psi_{2 q}}{\bar{\lambda}}
$$

と $F_{L}$ の線形結合となるため, 本稿では, 新しい状態変 数を $\boldsymbol{z}_{1}=\left[\begin{array}{ll}z_{11} & z_{12}\end{array}\right]^{\mathrm{T}}, \boldsymbol{z}_{2}=\left[\begin{array}{ll}z_{21} & z_{22}\end{array}\right]^{\mathrm{T}}$ と定義する.こ のとき, $z_{12}, z_{22}$ の相非対称性に起因する項は $\bar{\xi}_{2}, \bar{\xi}_{3}$ と比べて十分小さいため, $z_{12} \simeq \bar{\xi}_{2}, z_{22} \simeq \bar{\xi}_{2}$ となる.さ らに, $\bar{\xi}_{2}, \bar{\xi}_{3}$ を $\psi_{2}$ の回転角速度 $\omega_{\psi_{2}}=p \theta_{\psi_{2}}$ と同期し て回転する回転座標系 $\left(d^{\prime}-q^{\prime}\right.$ 座標系 $)$ の諸量

$$
\begin{aligned}
\psi_{2 d} & =\left|\psi_{2}\right| \cos \theta_{\psi_{2}}, \psi_{2 q}=\left|\psi_{2}\right| \sin \theta_{\psi_{2}} \\
{\left[\begin{array}{c}
i_{1 d} \\
i_{1 q}
\end{array}\right] } & =\left[\begin{array}{cc}
\cos \theta_{\psi_{2}} & -\sin \theta_{\psi_{2}} \\
\sin \theta_{\psi_{2}} & \cos \theta_{\psi_{2}}
\end{array}\right]\left[\begin{array}{l}
i_{F} \\
i_{T}
\end{array}\right] \\
\theta_{\psi_{2}} & =\tan ^{-1} \frac{\psi_{2 q}}{\psi_{2 d}}
\end{aligned}
$$

で表すと $\left(i_{F}\right.$ : 磁束成分電流, $i_{T}$ : 推力成分電流 $), z_{12}$, $z_{22}$ は近似的に $\bar{\xi}_{2}=\left|\psi_{2}\right| i_{F}, \bar{\xi}_{3}=\left|\psi_{2}\right| i_{T}$ と一致する. したがって， $z_{12}, z_{22}$ を制御するマイナーループを構成 すれば，ベクトル制御法における電流制御ループ4) と同 様の働きを持たせることができる ${ }^{3)}$. また, 推力 $F_{e}$ を直 接状態変数に選んでいるため, 推力制御も容易に行える.

つぎに, 状態座標変換 $(6) \sim(8)$ 式によって, 厳密な線 形化が可能となることを示す. $z_{1}, z_{2}$ の時間微分は,

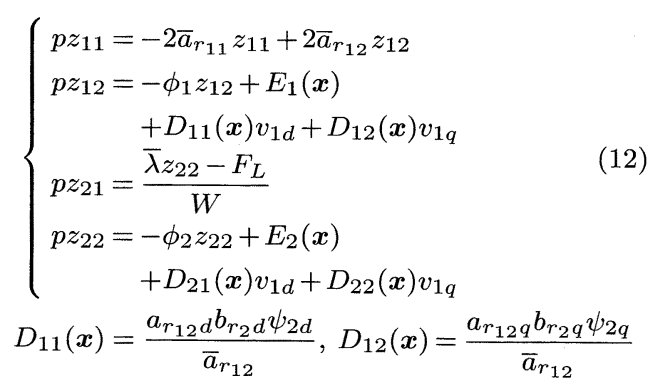

$$
\begin{aligned}
D_{21}(\boldsymbol{x})= & -\frac{\lambda_{d} b_{r_{2} d} \psi_{2 q}}{\bar{\lambda}}, D_{22}(\boldsymbol{x})=\frac{\lambda_{q} b_{r_{2} q} \psi_{2 d}}{\bar{\lambda}} \\
E_{1}(\boldsymbol{x})= & e_{11} \bar{\xi}_{1}+e_{12} \widetilde{\xi}_{1}+e_{13} \widetilde{\xi}_{2}+\omega_{2 e}\left(\bar{\xi}_{3}+e_{14} \widetilde{\xi}_{3}\right) \\
& +e_{15} \bar{\xi}_{4}+e_{16} \widetilde{\xi}_{4}+e_{17} \omega_{2 e} \psi_{2 d} \psi_{2 q} \\
E_{2}(\boldsymbol{x})= & \omega_{2 e}\left(e_{21} \bar{\xi}_{1}+e_{22} \widetilde{\xi}_{1}-\bar{\xi}_{2}+e_{23} \widetilde{\xi}_{2}\right)+e_{24} \widetilde{\xi}_{3} \\
& +e_{25} \psi_{2 d} \psi_{2 q}+e_{26} i_{1 d} i_{1 q} \\
\phi_{1}= & \bar{a}_{r_{11}}+\bar{a}_{r_{22}}+\frac{\widetilde{a}_{r_{12}}\left(3 \widetilde{a}_{r_{11}}+\widetilde{a}_{r_{22}}\right)}{\bar{a}_{r_{12}}} \\
\phi_{2}= & \bar{a}_{r_{11}}+\bar{a}_{r_{22}}+\frac{\widetilde{\lambda}\left(\widetilde{a}_{r_{11}}-\widetilde{a}_{r_{22}}\right)+\delta \widetilde{a}_{r_{12}}}{\bar{\lambda}}
\end{aligned}
$$

となる。ただし，紙面の関係上 $e_{i j}$ は省略した， $a_{r_{12} \star}$, $b_{r_{2} \star}, \lambda_{\star}, \bar{a}_{r_{12}}, \bar{\lambda}$ は正数であるから, 非干渉行列

$$
\boldsymbol{D}(\boldsymbol{x})=\left[\begin{array}{ll}
D_{11}(\boldsymbol{x}) & D_{12}(\boldsymbol{x}) \\
D_{21}(\boldsymbol{x}) & D_{22}(\boldsymbol{x})
\end{array}\right]
$$

はUで正則となる，したがって，Uで定義される

$$
\left[\begin{array}{l}
v_{1 d} \\
v_{1 q}
\end{array}\right]=\boldsymbol{D}^{-1}(\boldsymbol{x})\left[\begin{array}{l}
v_{1}-E_{1}(\boldsymbol{x}) \\
v_{2}-E_{2}(\boldsymbol{x})
\end{array}\right]
$$

を用いると，以下の厳密な線形化システムが得られる.

$$
\begin{aligned}
& \left\{\begin{array}{l}
p z_{1}=\left[\begin{array}{cc}
-2 \bar{a}_{r_{11}} & 2 \bar{a}_{r_{12}} \\
0 & -\phi_{1}
\end{array}\right] \boldsymbol{z}_{1}+\left[\begin{array}{l}
0 \\
1
\end{array}\right] v_{1} \\
y_{1}=\left[\begin{array}{ll}
1 & 0
\end{array}\right] \boldsymbol{z}_{1}
\end{array}\right. \\
& \left\{\begin{array}{l}
p z_{2}=\left[\begin{array}{cc}
0 & \bar{\lambda} \\
& \bar{W} \\
0 & -\phi_{2}
\end{array}\right] \boldsymbol{z}_{2}+\left[\begin{array}{l}
0 \\
1
\end{array}\right] v_{2}-\left[\begin{array}{c}
\frac{1}{W} \\
0
\end{array}\right] F_{L} \\
y_{2}=\left[\begin{array}{ll}
1 & 0
\end{array}\right] \boldsymbol{z}_{2}
\end{array}\right.
\end{aligned}
$$

なお，IM におけるベクトル制御法3)-5) と同様に $\left|\psi_{2}\right| \neq 0$ であると仮定したが, $\left|\psi_{2}\right|$ の目標值は正数であるから， 始動時以外で (14) 式は有効である.

\section{2 不可観測な状態の安定性とすべり周波数}

3.1 で定義した新しい状態变数の数は 4 であり, $x$ の 次数よりも 1 少ない. そこで, 新しい状態変数に $\eta=\theta_{\psi_{2}}$ を追加し, 出力 $y_{1}, y_{2}$ から不可観測なダイナミクスの安 定性を調べる。 $\eta$ の時間微分を求めると,

$$
p \eta=\omega_{2 e}+\frac{\bar{a}_{r_{12}} \bar{\xi}_{3}-\widetilde{a}_{r_{12}} \widetilde{\xi}_{3}+2 \widetilde{a}_{r_{11}} \psi_{2 d} \psi_{2 q}}{\bar{\xi}_{1}}
$$

となる. (15), (16) 式に対して設計される線形補償器に よって， $z_{i j}$ は一定值に制御されるから， $\boldsymbol{\psi}_{2}, \boldsymbol{i}_{1}$ は有界 である。したがって, $p \eta$ は有界となるため, 出力から不 可観測な状態 $\eta$ のダイナミクスは安定である。また，す ベり周波数 $\omega_{s l i p}=\omega_{\psi_{2}}-\omega_{2 e}$ は, (9), (10), (17) 式より

$$
\begin{aligned}
\omega_{s l i p}= & \widetilde{a}_{r_{11}} \sin 2 \theta_{\psi_{2}}-\frac{\widetilde{a}_{r_{12}} i_{F} \sin 2 \theta_{\psi_{2}}}{\left|\psi_{2}\right|} \\
& +\frac{i_{T}\left(\bar{a}_{r_{12}}-\widetilde{a}_{r_{12}} \cos 2 \theta_{\psi_{2}}\right)}{\left|\boldsymbol{\psi}_{2}\right|}
\end{aligned}
$$


となり， $2 \omega_{\psi_{2}}$ で振動することがわかる. (18) 式は参考 文献 2)での結果と一致している.

\section{3 磁束制御系および速度制御系の構成}

3.1 で述べた理由により, ベクトル制御法に㧍ける電 流制御器4)に相当する線形補償器として, PI 補償器

$$
v_{i}=k_{P_{i 2}}\left(z_{i 2}^{r e f}-z_{i 2}\right)+k_{I_{i 2}} \int_{0}^{t}\left(z_{i 2}^{r e f}-z_{i 2}\right) d t
$$

をマイナーループに用いる．また， $\left|\boldsymbol{\psi}_{2}\right|, V_{2 m}$ をそれら の目標值 $\psi_{2}^{r e f}, V_{2 m}^{r e f}$ に追従させるため, 以下の $\mathrm{I}-\mathrm{P}$ 補償器をメインループ（磁束制御ループ, 速度制御ルー プ）に用いる.

$$
z_{i 2}^{r e f}=-k_{P_{i 1}} z_{i 1}+k_{I_{i 1}} \int_{0}^{t}\left(z_{i 1}^{r e f}-z_{i 1}\right) d t
$$

ただし， $i=1,2$ であり，また， $z_{11}^{r e f}=\left(\psi_{2}^{r e f}\right)^{2}, z_{21}^{r e f}=$ $V_{2 m}^{r e f}$ である.このとき, 参考文献 3$)$ と同様に線形補償 器のパラメー夕を選ぶと, マイナーループ, メインルー プの入出力伝達関数は, それぞれ所望の 1 次遅れ系, 2 次振動系と（近似的に）一致する。 また, マイナールー プにより安定性を高めているため, パラメー夕変動など によって特異点 $\left|\psi_{2}\right|=0$ に落ち込む可能性は少ない.

\section{4. シミュレーション結果}

3. の議論では, 非線形補償と線形補償器を決定するた め, 2 次磁束の検出が可能であるとしたが, 実際には, 2 次磁束の検出は困難である. そこで, $(6) \sim(8),(14)$ 式に 含まれる 2 次磁束 $\psi_{2 d}, \psi_{2 q}$ を電流入力モデル

$$
\begin{aligned}
& p \widehat{\psi}_{2 d}=-a_{r_{11} d} \widehat{\psi}_{2 d}-\omega_{2 e} \widehat{\psi}_{2 q}+a_{r_{12} d} i_{1 d} \\
& p \widehat{\psi}_{2 q}=-a_{r_{11} q} \widehat{\psi}_{2 q}+\omega_{2 e} \widehat{\psi}_{2 d}+a_{r_{12} q} i_{1 q}
\end{aligned}
$$

で得られる推定值 $\widehat{\psi}_{2 d}, \widehat{\psi}_{2 q}$ に置き換えてシミュレーショ ンを行った. なお, シミュレーションでは, 相非対称性を考 慮していない間接形ベクトル制御法3),4) との比較を行っ ている. Figs. 2, 3よりべクトル制御法では $\left|\psi_{2}\right|, F_{e}$ に 脈動を生じているが，提案する非線形制御法では，操作 量である $\left|v_{1}\right|$ を脈動させることによって, $\left|\psi_{2}\right|, F_{e}$ の 脈動が抑えられていることが確認できる.

\section{5. おわりに}

本稿では, IM に対する参考文献 3) の結果を LIM の 場合に拡張した。.また, 提案法の有効性を検証するため にシミュレーションを行い, 推力や 2 次磁束に脈動のな い良好な制御が実現できることを確認した．提案法は間 接形ベクトル制御法2)のように 2 次磁束の推定器を電流 入力モデルに限定する必要はない3). 今後, 2 次磁束の推 定に磁束オブザーバ5)を用いることによって，パラメー

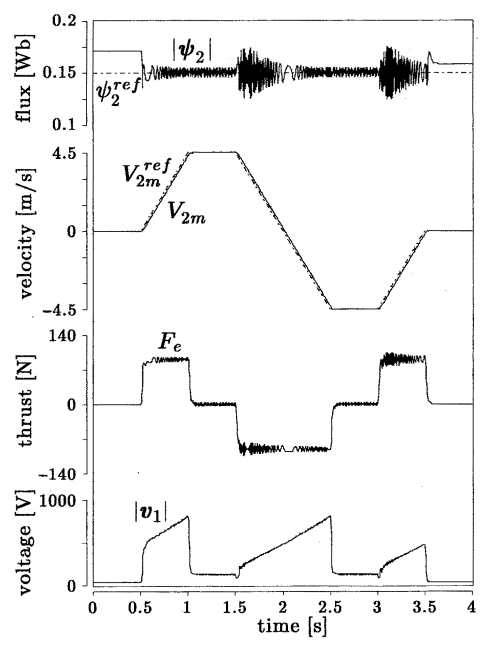

Fig. 2 Four quadrant operation of vector control method

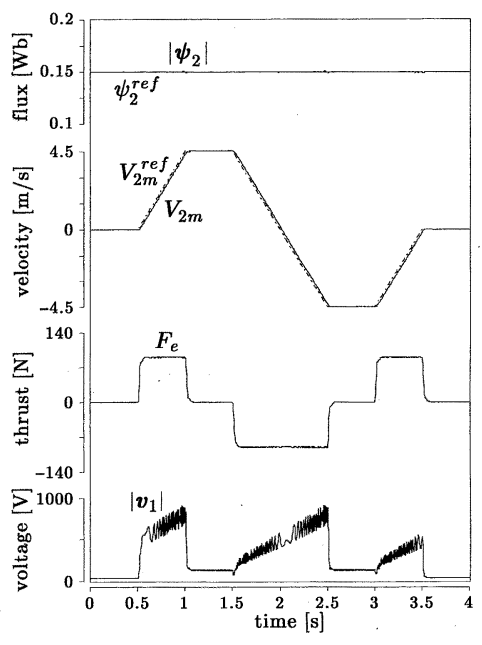

Fig. 3 Four quadrant operation of proposed method

夕変動に対する低感度化を実現することを検討したい.

\section{参.考文献}

1) 山田：産業用リニアモー夕, 工業調査会 (1981)

2) 杉本, 巴, 松村, 渡辺：リニア誘導モー夕の非対称定数を 考慮したベクトル制御法とその特性; 電気学会論文誌 D, Vol. 114, No. 1, pp. 17-24 (1994)

3) 川田, 森田, 亀井, 井上: 機械的な非線形性を考慮した誘導 モー夕の非干渉制御; 電気学会論文誌 C, Vol. 116, No. 11, pp. 1211-1218 (1996)

4) 杉本, 小山, 玉井：AC サーボシステムの理論と実際, 総合 電子出版社 $(1990)$

5) 堀, 梅野, 鈴木: 高速低感度磁束オブザーバに基づく磁界オ リエンテーション形ベクトル制御系の実現; 電気学会論文誌 D, Vol. 109, No. 10, pp. 771-777 (1989) 